\title{
A fuzzy ontology: on the relevance of ecocentrism in marine environmental ethics
}

\author{
Colin von Negenborn ${ }^{1}$
}

Received: 11 October 2021 / Accepted: 26 October 2021 / Published online: 22 November 2021

(c) The Author(s) 2021

\begin{abstract}
Governing human interaction in the maritime space implicitly rests on the ascription of value to this space. Environmental ethics helps to disentangle the many concepts of value that may come in conflict. As a particularly contested concept, ecocentrism assigns value not just at the atomistic level, but also at the holistic one. It has, however, been subject to criticism, thus challenging the validity of recent approaches to ocean management implicitly resting on ecocentric grounds. This paper provides a new justification for ecocentrism in the marine realm. Instead of relying on notions of community or teleonomy in nature, this paper builds on its ontology. It considers "the Area" beyond national jurisdiction and its declaration as "common heritage." While a shared understanding of this concept is necessary to put it to practice in the intergovernmental sphere, the paper argues that any characterization of its ontology is subject to fuzziness. In the light of disagreement, fluctuation, and uncertainty on the atomistic level, a holistic perspective on the Area is necessary. Ecocentrism thus allows to overcome the conceptual hindrances and facilitates the implementation of a genuinely common heritage.
\end{abstract}

Keywords Ocean governance $\cdot$ Environmental ethics $\cdot$ Common heritage $\cdot$ The Area $\cdot$ Ecocentrism

\section{Introduction}

Any scheme of maritime governance and any approach to managing affairs in and around the ocean ultimately rest on ethical presuppositions. Oftentimes, these presuppositions are left implicit. Unearthing them, however, is vital to understanding the normative validity of such governance, bridging the gap from

Colin von Negenborn

negenborn@philsem.uni-kiel.de

1 Department of Philosophy, Kiel University (Christian-Albrechts-Universität Zu Kiel, CAU),

Kiel, Germany 
evidence-based natural sciences to morally loaded political action. Furthermore, such understanding helps to reconcile conflicts between rivaling approaches to maritime affairs, elucidating commonalities and differences in the respective normative basis.

A key aspect of such ethical presuppositions is the relevant "unit" of moral concern. Most of our daily moral reasoning revolves around interactions between humans and takes an individualistic approach. That is, we are used to focusing on the rights and obligations of individual human beings. Some ethicists, however, argue that such approach is insufficient in the case where humans interact not (only) with one another, but also with the environment. Instead, they mandate a consideration of ecological collectivities, such as species or entire ecosystems. Here, the moral concern is not restricted to monadic individuals, but also encompasses composite entities. Such ecocentric or holistic approaches (a more precise terminology follows in Section 2.1) stand in contrast to individualistic reasoning.

Yet, ecocentrism has been subject to severe criticism and lost traction at least since the 1980 s, even being accused of leading to "environmental fascism" (Regan 1983, p. 362) or "eco-fascism" in short. But in spite of this criticism, a recent renaissance of ecocentric reasoning can be observed in the context of maritime affairs. An increasing number of papers-oftentimes from fields other than ethics-implicitly appeal anew to the value of ecological communities as a whole instead of focusing on the constituents of such communities. In the light of the past lines of attack, is this resurgence warranted?

This paper provides a novel justification for holistic arguments in the context of the ocean, particularly in the international domain. Instead of relying on arguments of teleonomy or retinity, which are prone to problems, it offers an ontological one. Why is ocean ontology relevant for maritime affairs, and why should such ontology involve holism?

With the marine realm transgressing national boundaries, international coordination in the management of marine space becomes increasingly important. This applies to both the high seas and the seabed underneath ("the Area"), where humans interact with nature and (indirectly) with one another. The resources - and potentially the marine life-of this seabed are declared "common heritage of mankind" by international convention. To put this concept of a common heritage to practice, and to reach functional schemes of governance for conservation and exploitation beyond national borders, it is necessary to have a shared understanding of what exactly this heritage is; i.e., there must be a shared ontology.

This ontology, in turn, must involve holistic aspects to get off the ground, as this paper argues. It offers three reasons why the Area is subject to a degree of "fuzziness," requiring holistic elements to capture its diffuse borders. First, there is political disagreement regarding the extent of the heritage-both among the United Nations' (UN) member states in general and among signatories of the UN Convention on the Law of the Sea (UNCLOS) in particular. Second, there is contentual fluctuation in the composition of the heritage due to species migration. Third, there is epistemic uncertainty given the vast majority of the biotope not yet 
being taxonomically classified. Taken together, these three characteristics yield a fuzzy ontology of the Area which eludes distinct description of its constituting elements. To ensure political practicability of the "common heritage" notion despite such fuzziness, holistic reasoning is warranted, shifting concern from a mere focus on particulars to an encompassing view. Else, the heritage will remain a theoretical construct.

The paper proceeds as follows. Section 2 sketches the key dimensions of marine ethics, focusing on the aspects most relevant for the argument. It introduces the concepts of ecocentrism and holism as well as the problems associated with them. Section 3 shows that arguments in favor and against ecocentrism have so far focused on a land-based ethic, and provides a new vindication of ecocentric approaches in the marine realm. Section 4 concludes.

\section{Ethics of the marine environment}

Ethical theories try to identify the "right" course of action in a particular setting. When the actions concern the relationship between humans and nature, the field of environmental ethics comes into play. It analyzes what we ought to when interacting with the environment, both in our actions towards the environment itself and in our actions towards other humans within this environment. These humans may be spatially or temporally distant from us; i.e., questions of international and intergenerational justice may come into play.

Since any scheme of ocean governance aims at implementing a certain outcome or action, it rests on some concept of the "good," on some theory of environmental ethic. Oftentimes, this normative grounding is not spelled out explicitly but left implicit as a "cryptonormative judgement" (Worsnip 2017, p. 4). This section therefore first sketches the relevant dimensions of such normative assumptions (2.1), with the divide between individualism and ecocentrism being one of them. This particular dimension is then analyzed in more details (Section 2.2) and the traditional, land-based objections to ecocentric views are presented (Section 2.3).

\subsection{Individualism and ecocentrism}

Most ethical theories - as well as every-day moral intuition-agree that we ought to consider the impact of our actions on others. They ascribe rights we must not infringe upon, or they assign values we must not diminish. But theories differ with respect to the potential bearer of such rights and values. In particular, they differ who can hold what kind of values. In the realm of environmental ethics, as relevant for the maritime space, we can distinguish between inherent and relational value. Inherent value assigns an entity moral status for its own sake. Relational values, on the other hand, link the assignment of such value to the interaction with other beings. Such interaction can serve a functional end or be of 
intrinsic worth. In the former case, the relation yields instrumental value, in the latter an eudaimonic one (Muraca 2011). ${ }^{1}$

Any ascription of value to natural entities now has to specify two dimensions. First, it must state how "deep" each value category reaches into nature. Is inherent worth exclusively reserved for humans, or also granted to (certain) animals? Can a shore be of eudaimonic worth by its sheer beauty, or does this concept only apply to living beings? This dimension also opens up the "demarcation problem," describing the extent of the moral community. Anthropocentrism restricts it to only contain human beings. Kant, for example, justifies this restriction by taking only humans to be rational, with animals possessing "only a relative value as means" (Kant 1964 [1785], p. 96). Physiocentrism, on the other hand, assumes criteria other than rationality or personhood to be relevant and thus extends the community to further natural beings. ${ }^{2}$ For an example in the marine realm, Singer takes the capacity to feel pain as a key driver and believes the dividing line to lie "somewhere between a shrimp and an oyster" (Singer 1975, p. 185). Extending the community even further, biocentrism takes everything that lives to have moral value (Taylor 1983).

The second dimension specifies the "unit" of value: do we consider the individual level, the collective, or both? Do groups of individuals-from anthropogenic groups such as families or nation states to environmental groups such as species or ecosystems - have a value of their own, beyond the aggregate value of their members? These questions lead to the distinction between individualistic and ecocentric views. The former take an atomistic approach and argue that every instance of value in the environment can be attributed to a particular individual being. The latter, in contrast, calls us to consider ecological collectivities in their entirety instead of focusing on their constituents. Holism takes a middle ground, assigning value both to composite groups such as species or ecosystems and to individuals. In this paper, we will refer to holism and ecocentrism interchangeably as both approaches depart from the prevalent notion of a purely individualistic ethic by their concern for ecological wholes. We now turn to the predominant forms and defenses of such ecocentric reasoning.

\subsection{Grounding ecocentricsm}

The standard notion of ecocentrism was coined by Aldo Leopold, who states in his Land Ethic that "[a] thing is right when it tends to preserve the integrity, stability, and beauty of the biotic community. It is wrong when it tends otherwise" (1949, p. 262). This marks a striking departure from a focus on the individual and shifts concern to the environment as a whole. Traditional defenses of such ecocentric reasoning can be described by two distinct strands of literature.

\footnotetext{
${ }^{1}$ As Ott and Kerschbaumer (2013, p. 109) point out, inherent (moral) and intrinsic (not necessarily moral) value are oftentimes used somewhat interchangeably in the literature, although they refer to different axiological categories.

${ }^{2}$ The exact extend and criteria differ between physiocentric theories. For an overview, see Palmer et al. (2014).
} 
The first strand builds ecocentrism on the grounds of retinity, i.e. the idea of interconnectedness. It argues that humanity is deeply intertwined with the surrounding environment and that individuals can thus not be considered in isolation. We are, in Leopold's words, "all interlocked in one humming community [...], one biota" (Leopold 1953, p. 148). And our membership in this community implies moral duties not just towards other members, but also towards the community as a whole. The goodness of our actions is not merely defined by their adherence to individual rights or the furthering of individual well-being, but instead " $[\mathrm{t}]$ he good of the community as a whole [...] serves as a standard for the assessment of the relative value" (Callicott 1980, p. 324; emphasis added). In a similar vein, the concept of a "deep ecology" (Naess 1989, p. 27) takes the integration of humans into ecological systems as a source of normative implications concerning the "right" behavior towards these systems.

The second strand provides a teleonomic justification for ecocentrism. It considers biotic communities as quasi-organisms of their own instead of mere collectives. These quasi-organisms have a "directedness" (télos) beyond those goals pursued by their members. Most prominently, Johnson argues "that ecosystems do have wellbeing interests, and that these interests are not merely aggregated interests of those beings within the system" (Johnson 1993, p. 216). Scholars differ on whether ecological wholes possess a strong form of "preference-interests" (Regan 1983, p. 87), rendering them being interested in something, or only a weaker form of "welfare-interests" (ibid.) which cause something to be in their interest. Either way, however, the interests thus ascribed to the whole go beyond the interests of the constituents and cause a teleonomy that ought to be of our moral concern.

\subsection{The many problems of ecocentric reasoning}

Ecocentric lines of thought have been subject to criticism ever since. However, it was not until the 1980s and $90 \mathrm{~s}$ that even proponents of ecocentrism abandoned the ship and its relevance in environmental ethics diminished. Before turning to the specific objections charged against the two strands above, we sketch the most prominent criticism of ecocentrism.

Recall first the respective assumptions each strand relies on: the argument based on retinity a morally loaded interconnectedness of humanity with nature, while the teleonomic argument hinges on the existence of genuine interests by ecological collectivities. A famous charge against ecocentrism, however, aims not at these assumptions but at their conclusion. Even if individuals are deeply interconnected with a (biotic) community, and even if this community pursues goals of its own, we must not subjugate the well-being of the individual to the welfare of the group as a whole. Doing so reduces an individual's moral status to her contribution to and relevance for the group. As such, it is tantamount to "environmental fascism" (Regan 1983, p. 362). If a person truly is "only a member of a biotic team" (Leopold 1949, p. 205), ecocentrism leads to repugnant 
conclusions if the interests of this person (who is of an abundant species, thus of little relevance for the ecosystem as a whole) come in conflict with the biotic community's integrity.

But even leaving the fervent - and possibly excessive-accusation of eco-fascism aside, ecocentrism is subject to criticism directed at both of the above sets of assumptions. Against the first strand-appealing to the intertwinement of humans and nature-critics raise the following dilemma. Either, they argue, the intertwinement is taken to be overly close-knit, claimed to be much closer than it in fact is. This concern is expressed by Steverson (1994, p. 78), who considers several forms of interspecies interaction that could substantiate a notion of "community" between humanity and the environment. All of these forms-predation, competition, symbiosis-are much weaker when it comes to the interaction of humans with other species than compared to the interaction among non-human species. The concept of intertwinement would thus need to be severely weakened, leading straight to the second horn of the dilemma: if any feeble degree of interconnectedness carries moral weight, then we ought to also assign moral value to cities or even the cosmos (Bratton 2004 , p. 4). Either way, the appeal to retinity-based arguments does not get ecocentrism off the ground.

Critics of the second strand question the ability of ecological wholes to form interests of their own and to pursue them. They argue that proponents of the teleonomic argument confuse practical and functional ends (Krebs 1999, p. 104). The former describes states of affairs which a bearer of interests seeks to implement by her own action. The agent chooses the respective action to accomplish the respective end. The latter, on the other hand, are mere outcomes of causal effects. Any apparatus may have a functional end, without its "pursuit" of such an end carrying any moral weight. Natural collectivities - such as forests or rivers-can follow functional ends at best (Ott and Kerschbaumer 2013, p. 111). While we ought to respect the practical ends of other moral agents, we do not have the same duties towards the functional ends of ecosystems.

\section{A new foundation of marine ecocentrism}

In the light of the above criticism, ecocentric and holistic approaches appear like a lost cause. This seems to apply not only to the discipline of environmental ethics in theory, but also to the normative grounding of maritime governance in practice. However, this section offers a new vindication for ecocentric reasoning in the marine realm. It starts by arguing why such new vindication is of interest in the first place (Section 3.1). It then paves the ground for defense of ecocentrism not based on teleonomy or retinity, but on ontological grounds. To this end, it first describes a particular ontology in the marine space-namely the Area as "common heritage" (Section 3.2). It proceeds by explaining why this ontology is subject to a certain "fuzziness" and why it hence requires a holistic perspective to be functional (Section 3.3). This way, ecocentric and holistic reasoning gains new traction as an ethical basis in maritime affairs. 


\subsection{Why bother?}

Given the argumentative weaknesses of both strands of ecocentrism, why not abandon the project altogether and return to purely individualistic approaches to environmental ethics? There are two reasons why a closer look is of interest in the particular case of marine environmental ethics, and thus in the normative groundwork of maritime affairs.

First, and most importantly, past rationales for ecocentric reasoning have implicitly focused on humanity's interaction with the terrestrial environment. This focus is most apparent in Leopold's concept of a "Land Ethic" in his seminal work (1949), constituting the basis for subsequent literature on ecocentrism. Even Callicott, one of the early proponents of the retinity-based strand, acknowledged that his argument-relying on the interconnectedness of humans with other species-does not quite get off the ground in the context of marine ecosystems (Callicott 1997, p. 4). Few authors have tried to flesh out a genuinely marine environmental ethic, ${ }^{3}$ and none seems to have provided a defense of marine ecocentrism.

Second, elaborating new grounds for ecocentrism in the debate on maritime affairs is not merely a theoretical exercise for its own sake, but also a practical necessity. Recently, an increasing number of approaches to ocean governance hasoftentimes implicitly-relied on ecocentric reasoning (or holistic, that is-recall that both terms are used interchangeably here). Moral value is no longer reserved for individuals - be they human or not-with ecosystems as a whole being left with instrumental or economic value. Instead, there is now talk about "the intrinsic value of the ocean" (Dupont and Fauville 2017, p. 519), giving us "an ethical and moral duty to respect and protect the ocean" (ibid., p. 520). That is, the obligation of environmental protection and wise governance no longer stems from our duties towards particular human beings or animals suffering from our exploitation of the sea, but from a duty towards the ocean as a whole.

The reasoning of such approaches focuses on the deontological dimension of humanity's interaction with the ocean by defining rights and duties. Others emphasize the axiological dimension by specifying values: they define, for example, the "EIV [ecosystem intrinsic value] for coastal and marine ecosystems" (Ye et al. 2020 , p. 10) as "the objective value of the ecosystem in and for itself" (ibid., p. 3; emphasis removed) and seek to quantify this value for specific case study areas. Some authors ascribe holistic values to specific aspects of the ocean, e.g., by arguing that "marine biodiversity has intrinsic value of its own" (Reuchlin-Hugenholtz and McKenzie 2015, p. 6), while others stipulate "ocean values" (Laffoley et al. 2021, p. 1513) more broadly. This renaissance of (implicit) ecocentrism is not limited to the selected academic writing. Empirical surveys show that ecocentric reasoning is spreading in marine ecologists' reasoning (Shilin et al. 2003, p. 254) and also among a wider set of stakeholders who "articulated intrinsic values" (O'Connor and Kenter 2019, p. 1255) in interviews on marine ecosystems.

\footnotetext{
3 There are notable exceptions, see Miller and Kirk (1992) as well as-more recently_Ott (2021).
} 
Thus, despite the difficulties of embracing an ecocentric land ethic, it seems worthwhile to vindicate such approach in the marine realm. Doing so would substantiate those proposals for maritime governance which implicitly rest on ecocentric reasoning. While Callicott (1999) abandoned ecocentrism altogether given the criticism sketched above, this paper tries to avoid throwing out the baby with the seawater.

\subsection{The common heritage}

The use of the maritime realm by humans has consequences that span both time and space. Furthermore, vast areas of the oceans lie beyond national jurisdiction. Hence, international coordination in the preservation and exploitation of the sea is a necessity. To achieve such coordination, however, it is vital to share an understanding of what there is to be preserved-and potentially exploited. That is, a common ontology of the sea, and particularly of its internationally shared resources, is essential.

An important step into this direction was taken by the international community through the United Nations Convention on the Law of the Sea (UNCLOS 1982). It defined the high seas as the water column beyond the countries' exclusive economic zones and territorial waters (Art. 86), comprising about two-thirds of the ocean. Similarly, the Area denotes those parts of the seabed that do not belong to any country's legal continental shelf (Art. 1(1)); i.e., it spans the ocean floor beyond national jurisdiction and covers roughly half of the seabed.

Crucially, UNCLOS specified that " $[\mathrm{t}]$ he Area and its resources are the common heritage of mankind" (Art. 136). The notion of a "common heritage" is not so much a concept of joint ownership as of joint stewardship (van Doorn 2016, p. 194). It acknowledges both an international and an intergenerational dimension of justice (ibid., p. 193) and takes "the benefit of mankind as a whole" (Art. 140) as a criterion for just exploitation of the Area. The heritage in its entirety is subject to our providence, mandating a sustainable utilization of the whole.

In spite of these noble goals, their implementation has been plagued by hindrances. Challenges become particularly visible in the International Seabed Authority's (ISA) attempt to regulate activities in the Area. First, it is unclear which activities actually do further the benefit of humanity as a whole (Moses and Brigham 2021). Second, if certain activities are permitted and the fruits thus reaped are to be distributed, what is a just allocation, both spatially and temporally (Lodge et al. 2017)? International management of the marine environment thus raises deeply normative questions. But before answering the moral questions of how to manage this environment, one should ask the ontological question of what it actually consists of. We now turn to this question.

\subsection{A fuzzy ontology}

The many ontologies of the marine realm have been of repeated scientific concern. Understanding what we take the ocean to be is not merely an academic exercise for its own sake, but has immediate political and governmental implications (Yates et al. 
2017). However, scholars have so far focused on the nature of such "wet" ontologies in contrast to terrestrial ones (Peters and Steinberg 2015), or confined the scope of their analysis to the national domain (Bear 2013). The essential characteristics of international waters, their resources, and the life therein, have eluded a concise account. In the following, it is argued that any attempt at providing such account will be prone to fuzziness for three reasons: political disagreement, contentual fluctuation, and epistemic uncertainty. In order to arrive at a functional understanding of the "common heritage" idea in the light of this fuzziness, holistic reasoning is required.

First, there currently is political disagreement among the nation states on what the resources in the Area comprise. The minimum extent, as specified by UNCLOS, denotes "all solid, liquid or gaseous mineral resources" (Art. 133 (a), emphasis added). Some nations, however, urge for an extension of this concept to marine genetic resources (Leary 2019), which would vastly increase the extent of the heritage to basically any living organism in the Area. Such an extension would also be in line with the ambitious vision of Pardo, a key figure in the establishment of UNCLOS. He called for an international agency "to administer in the interests of mankind the oceans and [not just] the ocean floor beyond national jurisdiction" (United Nations 1967, p. 1). While such agency was established indeed (the ISA), its scope was limited to the seabed, excluding the water column above. To date, no consensus is reached towards broadening the extend of the heritage.

Second, consider particular concepts of extending the common heritage. These range from the abovementioned, rather narrow set-encompassing not only the seabed's mineral resources, but also its genetic ones-over the more ambitious idea of including all fisheries in international waters (Sackel 2017) to Pardo's bold vision of covering the high seas in their entirety. Each of these extensions would, however, increase the fluctuation of the heritage even further. Already now, the movement of "highly migratory species" between different zones of jurisdiction is of concern to UNCLOS (Art. 64). Applying the common heritage principle to sedentary species in the Area, or outright to all fish in the high seas, pushes the fluctuation to additional degrees. The border between nationally exploitable resources and humanity's common heritage becomes increasingly blurred.

Third, and finally, let us assume that consensus was reached on the question which resources are part of the common heritage-only mineral resources, also genetic ones, or subsets thereof-and that the fluctuation of these resources-into and outside of the area beyond national jurisdiction - was accounted for. Even then, the extent of the heritage would be severely underspecified. This is due to the epistemic uncertainty surrounding the marine realm. For one, more than $90 \%$ of the marine species are believed to be not yet taxonomically classified (Mora et al. 2011). Furthermore, if the resources belonging to the common heritage are to be exploited, e.g., via deep sea mining, such activities will impact the heritage's composition and value. To date, however, there is very limited information on these impacts (Levin et al. 2020, p. 787). Any use of the international marine resources in the Area, even if it is to the benefit of humanity as a whole, will thus affect these very resources in an uncertain way. 
Characterizations of the international marine realm, particularly of the Area, are thus subject to a lack of consensus and information. For the three reasons above, the notion of a common heritage is a blurry one. Disagreement, fluctuation, and uncertainty cause any ontological description to be fuzzy. Yet, sharing an ontology of the heritage is vital for the concept to get off the ground. As long as we try to pinpoint the exact extent of the heritage by specifying its individual constituents, the idea will remain a potentially never-ending theoretical exercise. But in the light of humanity's ever increasing impact on the maritime space, and with the relevance of this space for many ecosystems (including humans) in mind, we cannot wait to settle these three issues in every detail. Instead of aiming at a full characterization of the heritage's composition, we must content ourselves with a holistic understanding of the international marine space, requiring wise governance of the whole.

This holism does not merely resemble an ecosystem service approach, preserving the integrity of biotopes for the sake of their total economic value. Instead, it assigns fundamental relational value to the marine ecosystem: relational by its designation to benefit humanity as a whole, and fundamental by this benefit not being reducible to economic profits, but instead contributing to "a meaningful human life" in different ways (Muraca 2011, p. 383). Facilitating "meaningful lives" internationally and intergenerationally obliges us to share the common heritage in a just manner. This, in turn, necessitates coordinated management of the ocean beyond national jurisdiction. To succeed on the international level despite the three hindrances, we must include ecocentric perspectives, shifting the focus from atomistic uncertainties and blurry boundaries to an ecological collectivity. Where individualistic approaches fail, holistic ones must rise.

\section{Conclusion}

Ecocentrism has been the problem child of environmental ethicists for long. In contrast to individualistic ethics, ecocentrism assigns moral value not (just) to particulars, but also to composite entities such as species or entire ecosystems. Holistic views similarly depart from the sole focus on the individual towards considering ecological wholes. But both holism and ecocentrism have been subject to criticism due to the normative basis they are built on. Neither arguments based on teleonomy nor those appealing to retinity could provide sufficient grounds. The former appeals to the deep interconnectedness of the human species with other parts of nature, alleging a disentanglement to the individual level to be impossible and necessitating a concern with the intertwined system as a whole. This interconnectedness, however, was put into question by the arbitrary concept of ecological collectivities it is built on. The latter instead relies on the assumption of genuine interests at the level of ecosystems, extending beyond the mere interests of the constituting individuals. This view, in turn, was criticized for confusing the notion of interests and of the ends thus pursued. While rational individuals do indeed follow practical ends, collectivities only resemble automata in following functional ends as a result of causal relations instead of true interests. 
Despite said opposition, this paper called for a rehabilitation of ecocentric reasoning. The call was motivated by two observations. First, past vindications of and objections to ecocentrism focused on a land-based ethic. Since environmental ethics studies the moral dimensions of humanity with nature, this undue restriction omits the marine realm. Second, recent work has implicitly reintroduced ecocentric arguments into the debate on "good" ocean governance. To assess the validity of such arguments, their normative grounding must be evaluated. Can ecocentrism be substantiated in context of the oceans?

Three arguments provide new support. They focus on those parts of the ocean which lie beyond national jurisdiction. The seabed underneath these waters, called "the Area," has been declared "common heritage of mankind," and many voices favor an extension of this concept to the waters above the seabed as well as to the marine life therein. But the extent of said "common heritage" eludes a concise characterization for three reasons: political disagreement, contentual fluctuation, and epistemic uncertainty. These factors impede any attempt to provide a particularistic account of the international marine realm, describing the heritage by its constituents. But for the heritage to truly further "the benefit of mankind as a whole" (UNCLOS Art. 140), we need the nation states to share a common ontology. In the light of the aforementioned difficulties, we must drop purely individualistic accounts in favor of holistic ones. Only if we acknowledge the heritage's blurry boundaries and the impossibility to capture it by its components, we will succeed in putting the morally loaded concept of a common heritage to practice. A holistic understanding of the marine resources in (and underneath) international waters is necessary to do justice both across generations and across national borders. This paper provides some groundwork in the philosophical domain, but much work remains in the political one.

Acknowledgements The author benefitted from helpful comments by audiences at the European Workshop on Maritime Systems Resilience and Security (MARESEC 2021) and at the conference on Waterworlding 2021 as well as by two anonymous referees. A previous version of this text was titled "One Ocean, One Heritage? A New Foundation of Ecocentrism in Marine Environmental Ethics."

Funding Open Access funding enabled and organized by Projekt DEAL.

\section{Declarations}

Conflict of interest The author declares no competing interests.

Open Access This article is licensed under a Creative Commons Attribution 4.0 International License, which permits use, sharing, adaptation, distribution and reproduction in any medium or format, as long as you give appropriate credit to the original author(s) and the source, provide a link to the Creative Commons licence, and indicate if changes were made. The images or other third party material in this article are included in the article's Creative Commons licence, unless indicated otherwise in a credit line to the material. If material is not included in the article's Creative Commons licence and your intended use is not permitted by statutory regulation or exceeds the permitted use, you will need to obtain permission directly from the copyright holder. To view a copy of this licence, visit http://creativecommons.org/licen ses/by/4.0/. 


\section{References}

Bear C (2013) Assembling the sea: materiality, movement and regulatory practices in the Cardigan Bay scallop fishery. Cult Geogr 20:21-41. https://doi.org/10.1177/1474474012463665

Bratton SP (2004) Thinking like a Mackerel: Rachel Carson's "Under the Sea-Wind" as a source for a trans-ecotonal sea ethic. Ethics Environ 9:1-22

Callicott JB (1980) Animal liberation: a triangular affair. Environ Ethics 2:311-338

Callicott JB (1997) Whaling in Sand county: a dialectical hunt for land ethical answers to questions about the morality of Norwegian minke whale catching. Colo J Int Environ Law Policy 8:1-30

Callicott JB (1999) Holistic environment ethics and the problem of ecofascism. In: Callicott JB (ed) Beyond the land ethic: more essays in environmental philosophy. State Univ. of New York Press, Albany, NY, pp 59-78

Dupont S, Fauville G (2017) Ocean literacy as a key toward sustainable development and ocean governance. In: Handbook on the Economics and Management of Sustainable Oceans. Edward Elgar Publishing, Cheltenham, UK

Johnson LE (1993) A morally deep world: an essay on moral significance and environmental ethics. Cambridge University Press, Cambridge

Kant I (1964) [1785], Groundwork of the metaphysic of morals. Harper Torchbooks, New York

Krebs A (1999) Ethics of nature. de Gruyter, Berlin

Laffoley D, Baxter JM, Amon DJ et al (2021) Evolving the narrative for protecting a rapidly changing ocean, post-COVID-19. Aquat Conserv Mar Freshwat Ecosyst 31:1512-1534

Leary D (2019) Agreeing to disagree on what we have or have not agreed on: the current state of play of the BBNJ negotiations on the status of marine genetic resources in areas beyond national jurisdiction. Mar Policy 99:21-29. https://doi.org/10.1016/j.marpol.2018.10.031

Leopold A (1949) A Sand County almanac. Oxford University Press, Oxford

Leopold A (1953) Round river. Oxford University Press, Oxford

Levin LA, Amon DJ, Lily H (2020) Challenges to the sustainability of deep-seabed mining. Nature Sustainability 3:784-794. https://doi.org/10.1038/s41893-020-0558-X

Lodge MW, Segerson K, Squires D (2017) Sharing and preserving the resources in the deep sea: challenges for the international seabed authority. Int J Mar Coast Law 32:427-457. https://doi.org/ $10.1163 / 15718085-12323047$

Miller ML, Kirk J (1992) Marine environmental ethics. Ocean Coast Manag 17:237-251. https://doi. org/10.1016/0964-5691(92)90012-A

Mora C, Tittensor DP, Adl S et al (2011) How many species are there on earth and in the ocean? PLoS Biol 9:e1001127. https://doi.org/10.1371/journal.pbio.1001127

Moses JW, Brigham AM (2021) Whose benefit? A comparative perspective for the ISA. Mar Policy 131:104550. https://doi.org/10.1016/j.marpol.2021.104550

Muraca B (2011) The map of moral significance: a new axiological matrix for environmental ethics. Environ Values 20:375-396. https://doi.org/10.3197/096327111X13077055166063

Naess A (1989) Ecology, community and lifestyle: outline of an ecosophy. Cambridge University Press, Cambridge

O'Connor S, Kenter JO (2019) Making intrinsic values work; integrating intrinsic values of the morethan-human world through the Life Framework of Values. Sustain Sci 14:1247-1265. https://doi. org/10.1007/s11625-019-00715-7

Ott K (2021) Ocean ethics: environmental ethics and environmental justice as foundation of SDG 14. Mimeo

Ott K, Kerschbaumer L (2013) Maintaining a river's healthy life? An inquiry on water ethics and water praxis in the upstream region of China's Yellow River. Water Altern 6:107-124

Palmer C, McShane K, Sandler R (2014) Environmental ethics. Annu Rev Environ Resour 39:419_ 442. https://doi.org/10.1146/annurev-environ-121112-094434

Peters K, Steinberg P (2015) Wet ontologies, fluid spaces: giving depth to volume through oceanic thinking. Environment and Planning d: Society and Space 33:247-264. https://doi.org/10.1068/ d14148p

Regan T (1983) The case for animal rights. University of California Press, Berkeley

Reuchlin-Hugenholtz E, McKenzie E (2015) Marine protected areas: smart investments in ocean health. World Wide Fund for Nature (WWF), Gland, Switzerland 
Sackel J (2017) Food justice, common heritage and the oceans: resource narratives in the context of the Third United Nations Conference on the Law of the Sea. Int J Marit Hist 29:645-659. https:// doi.org/10.1177/0843871417713682

Shilin MB, Durning D, Gajdamaschko N (2003) How American ecologists think about coastal zone environments. In: Dallmeyer DG (ed) Values at Sea: Ethics for the Marine Environment. University of Georgia Press, Athens, Georgia, pp 239-259

Singer P (1975) Animal liberation: a new ethics for our treatment of animals. New York Review, New York

Steverson BK (1994) Ecocentrism and ecological modeling. Environ Ethics 16:71-88

Taylor PW (1983) In defense of biocentrism. Environ Ethics 5:237-243

United Nations (1967) UN General Assembly, 22nd session: 1st Committee, 1516th meeting - UN Doc A/C.1/PV.1516

United Nations Convention on the Law of the Sea (1982) UNCLOS. 21 ILM 1245

van Doorn E (2016) Environmental aspects of the Mining code: preserving humankind's common heritage while opening Pardo's box? Mar Policy 70:192-197. https://doi.org/10.1016/j.marpol.2016.02. 022

Worsnip A (2017) Cryptonormative judgments. Eur J Philos 25:3-24. https://doi.org/10.1111/ejop.12208

Yates JS, Harris LM, Wilson NJ (2017) Multiple ontologies of water: politics, conflict and implications for governance. Environ Plan D 35:797-815. https://doi.org/10.1177/0263775817700395

Ye S, Zhang L, Feng H (2020) Ecosystem intrinsic value and its evaluation. Ecol Model 430:109131. https://doi.org/10.1016/j.ecolmodel.2020.109131

Publisher's note Springer Nature remains neutral with regard to jurisdictional claims in published maps and institutional affiliations. 